\title{
Bone Marrow Karyotypes of Children with Nonlymphocytic Leukemia
}

\author{
A. HAGEMEIJER, G. E. VAN ZANEN, E. M. E. SMIT, AND K. HÄHLEN \\ Department of Cell Biology and Genetics (A. H., E. M. E. S.) and Department of Pediatric Oncology (G. E. V. Z., K. \\ H.) Sophia Children's Hospital, Erasmus University, Rotterdam, The Netherlands
}

\begin{abstract}
Summary
Bone marrow (BM) karyotypes from 16 consecutive children presenting with nonlymphocytic leukemia were established with the use of banding techniques, before therapy. The two patients with chronic myeloid leukemia (CML) showed the Philadelphia $\left(\mathrm{Ph}^{1}\right)$ translocation $(9 q+; 22 q-)$. Five of the 14 patients with an acute nonlymphocytic leukemia (ANLL) presented no acquired cytogenetic abnormalities, but one of these five showed a high level of hypodiploidy. One patient with AML evidenced a variant of the $\mathrm{Ph}^{1}$ chromosome originated as a translocation $(12 \mathrm{p}+; 22 \mathrm{q}-)$. Nonrandom abnormalities $(-7 ; 7 q-;+8 ; t(8 ; 21) ;-21)$ were found in six patients, isolated or in association with other aberrations. Among the random abnormalities, apparently balanced translocations and chromosomal deletions were observed.

In ANLL, no correlation could be found between morphologic diagnosis and cytogenetic findings. On the other hand, the presence of BM cells with a normal karyotype at diagnosis was associated with an improved remission rate and survival time. Followup studies were performed in four ANLL patients with an abnormal cell clone at diagnosis. Three of them achieved hematologic remission; their BM karyotype was found to be normal at that stage. In the 4th patient, generalization of the abnormal karyotype in BM cells was seen in the terminal phase of the disease.
\end{abstract}

\section{Speculation}

Chromosome identification techniques have greatly improved our knowledge of acquired BM aneuploidy found in leukemia. Nonrandom patterns of abnormalities have been found. Analyses of larger series of patients using advanced banding techniques and systematic followup studies will ascertain the significance of these cytogenetic abnormalities for diagnosis, prognosis, and neoplastic transformation.

Recent publications on BM cytogenetic analysis in adult patients with chronic and acute nonlymphocytic leukemia have indicated that chromosomal abnormalities occur in a nonrandom fashion $(11,14,19,22,23)$. The $\mathrm{Ph}^{1}$ chromosome, characteristic of CML in the adult, has been identified as a translocation of the major part of the long arm of chromosome 22 onto another chromosome, usually the long arm of 9 (19), although other chromosomes than 9 are involved in roughly $10 \%$ of the cases (28). In ANLL chromosomal abnormalities were observed in 40-50\% of the cases. In adults with acute myeloid leukemia (AML), acute myelomonocytic leukemia (AMMoL) and erythroleukemia (EL) there appears to be a large excess of monosomy 7 , trisomy 8 , trisomy 9, and, less frequently, abnormalities in chromosome 17, trisomy 19 , and trisomy or monosomy 21 . Translocation $(8 ; 21)$ and $(15 ; 17)$ are more particularly associated with AML and acute promyelocytic leukemia (APL), respectively $(21,22)$.

In childhood, nonlymphocytic leukemia are uncommon forms of leukemia and there are only a few reports of BM cytogenetic studies with modern banding techniques. The $\mathrm{Ph}^{1}$ chromosome may be found in some cases of childhood $\mathrm{CML}$, and its presence can differentiate the adult type of CML with its more protracted course, from the juvenile variant. Nonrandom acquired abnormalities have also been reported in a small number of children with ANLL: monosomy 7 was reported three times in AML, AMMoL, and $\operatorname{EL}(7,10,17)$ deletion $7 \mathrm{q} 22$ was found twice in AML (9), and monosomy 9 was described once in AML (8). An extensive report of cytogenetic abnormalities in childhood leukemia has been published by Zuelzer et al. in 1976 (31), but it deals mainly with acute lymphocytic leukemia; furthermore, this study started before the use of banding techniques, making the karyotypes difficult to interpret.

In order to investigate the occurrence of abnormal karyotypes in children with nonlymphocytic leukemia, cytogenetic analyses were systematically performed in children with these disorders. These are the findings in 16 children: two cases of CML and 14 cases of ANLL.

\section{MATERIALS AND METHODS}

\section{PATIENT MATERIAL}

Between August 1973 and June 1978, 16 children presented in our Pediatric Department with nonlymphocytic leukemia and had cytogenetic analysis of their BM cells performed before any treatment. Patients particulars, diagnoses, initial hematologic and clinical findings, and results of treatment are summarized in Table 1.

Before BM aspiration, informed consent was obtained from the children's parents according to the declaration of Helsinki. BM aspirates were routinely taken from the posterior iliac crest in children and from the tibia in infants. Morphologic diagnosis was made on BM and blood smears stained with May GrünwaldGiemsa and was confirmed by histochemical staining techniques including Sudan-Black, myeloperoxidase, P.A.S., acid and alkaline phosphatase. Smears were independently examined by two different groups of investigators.

Morphologic and histochemical studies led to the diagnosis of CML in two patients, AML in four patients, APL in two patients, $A M M o L$ in five patients, and EL in three patients.

In ANLL, hematologic remission was defined as the absence of blast cells in peripheral blood and the presence of less than $5 \%$ blast cells in BM. Complete remission was defined as a hematologic remission combined with the absence of extramedullary involvement.

All patients with ANLL, except one, initially received similar induction therapy consisting of 4-6 courses of cytosine-arabinoside (ARA-C) and cyclophosphamide (CYT). Each course included four days medication with three days rest. When remission was obtained, maintenance therapy with 6-mercaptopurine was started and 6-8 wk later, central nervous system (CNS) prophylaxis was given. This consisted of cranial irradiation and five intrathecal doses of ARA-C. Thereafter, a single reinducer course with ARA-C and CYT was given every 6 wk during maintenance 
Table 1. Clinical data

\begin{tabular}{|c|c|c|c|c|c|c|c|c|c|c|c|c|c|c|c|c|}
\hline \multirow[b]{3}{*}{ No. } & \multirow[b]{3}{*}{ Sex } & \multirow{3}{*}{$\begin{array}{c}\text { Patients } \\
\\
\text { Age } \\
(y r)^{1}\end{array}$} & \multirow[b]{3}{*}{ Diagnosis } & \multicolumn{10}{|c|}{ Initial Findings } & \multicolumn{3}{|c|}{ Evolution } \\
\hline & & & & \multirow[b]{2}{*}{$\begin{array}{c}\mathrm{Hb} \\
(\mathrm{gr} / \mathrm{dl})\end{array}$} & \multicolumn{2}{|c|}{ Peripheral blood } & \multicolumn{3}{|c|}{ Bone marrow } & \multicolumn{4}{|c|}{ Clinical Symptoms } & \multicolumn{2}{|c|}{ Duration } & \multirow{2}{*}{$\begin{array}{l}\text { Survival } \\
\text { Month }^{5}\end{array}$} \\
\hline & & & & & $\begin{array}{c}\text { Platelets } \\
\left(10^{9} / 1\right)\end{array}$ & $\begin{array}{c}\text { cells } \\
\left(10^{9} / 1\right)\end{array}$ & $\begin{array}{c}\text { Blast } \\
(\%)\end{array}$ & $\begin{array}{l}\text { Cellular- } \\
\text { ity }\end{array}$ & $\begin{array}{c}\text { Blast } \\
(\%)\end{array}$ & $\begin{array}{l}\text { Liver } \\
(\mathrm{cm})^{2}\end{array}$ & $\begin{array}{l}\text { Spleen } \\
(\mathrm{cm})^{2}\end{array}$ & $\begin{array}{l}\text { Lymph } \\
\text { nodes }\end{array}$ & Other & $\begin{array}{c}\text { HR } \\
\text { month }^{3} \\
\end{array}$ & $\begin{array}{c}\text { CR } \\
\text { month }^{4}\end{array}$ & \\
\hline 1 & $\mathrm{~F}$ & 4 & CML & 5.9 & 509 & 426 & 4 & High & & 0 & 11 & - & & & & $75+$ \\
\hline 2 & $F$ & $39 / 12$ & CML & 10.1 & 260 & 189 & 4 & High & & 2 & 12 & - & & & & $59+$ \\
\hline 3 & $\mathbf{M}$ & $59 / 12$ & AML & 10.5 & 16 & 118 & 88 & High & 95 & 4 & 12 & + & & 6 & 4 & 11 \\
\hline 4 & $\mathbf{M}$ & $810 / 12$ & AML & 7.5 & 53 & 46.6 & 77 & High & 99 & 0 & 0 & - & & 6 & 6 & 15 \\
\hline 5 & $\mathbf{M}$ & $311 / 12$ & AML & 9.1 & 60 & 118 & 76 & High & 36 & 6 & 10 & + & & $24+$ & $24+$ & $26+$ \\
\hline 6 & $\mathbf{M}$ & $79 / 12$ & AML & 8.0 & 115 & 7 & 52 & High & 62 & 0 & 0 & - & $\begin{array}{c}\text { Pneumococcal } \\
\text { meningitis }\end{array}$ & $12+$ & $12+$ & $16+$ \\
\hline 7 & $\mathbf{M}$ & $12 / 12$ & APL & 5.0 & 65 & 17.8 & 68 & Normal & 70 & 3 & 0 & + & & 0 & 0 & $1 / 2$ \\
\hline 8 & $\mathrm{~F}$ & 6 & APL & 5.5 & 50 & 17.7 & 6 & Normal & 48 & 5 & 2 & - & & $1+$ & $1+$ & $3+$ \\
\hline 9 & $\mathrm{~F}$ & $104 / 12$ & AMMoL & 11.0 & 90 & 33.9 & 25 & Normal & 30 & 0 & 0 & + & Skin infiltration & 0 & 0 & 6 \\
\hline 10 & $\mathbf{M}$ & $510 / 12$ & AMMoL & 6.7 & 20 & 6.6 & 37 & Low & 25 & 2 & 3 & - & & 0 & 0 & 1 \\
\hline 11 & $\mathbf{M}$ & $810 / 12$ & AMMoL & 8.1 & 38 & 5.6 & 47 & Normal & 99 & 7 & 0 & + & & 6 & 6 & 17 \\
\hline 12 & $F$ & 2 wks. & AMMoL & 8.6 & none & 155 & 53 & High & 57 & 5 & 6 & - & $\begin{array}{l}\text { At birth skin in- } \\
\text { filtration }\end{array}$ & 0 & 0 & 4 \\
\hline $13^{6}$ & $\mathbf{M}$ & $12 / 12$ & AMMoL & 6.1 & 63 & 12.8 & 25 & Normal & 43 & 3 & 1 & + & Skin infiltration & $1 / 2+$ & 0 & $31 / 2+$ \\
\hline 14 & $\mathbf{M}$ & 12 & EL & 6.7 & 67 & 1.1 & 62 & Normal & 99 & 0 & 0 & - & $\begin{array}{l}\text { Down's syn- } \\
\text { drome }\end{array}$ & 21 & 21 & 29 \\
\hline 15 & $\mathrm{~F}$ & $26 / 12$ & EL & 4.3 & 13 & 35.4 & 67 & Low & 82 & 5 & 11 & + & & 2 & 2 & $51 / 2$ \\
\hline 16 & $\mathbf{M}$ & $10 / 12$ & $\mathrm{EL}$ & 6.6 & 2 & 8.2 & 10 & Normal & 99 & 3 & 5 & + & & 0 & 0 & 7 \\
\hline
\end{tabular}

'Age at the time of diagnosis.

${ }^{2} \mathrm{Cm}$ below costal margin.

${ }^{3}$ Hematological remission.

${ }^{4}$ Complete remission.

${ }^{5}$ Patients still alive August 1, 1978 are indicated with + .

${ }^{6}$ After submission of this publication, patient 13 showed a rapid fatal evolution. Remission of CNS leukemia was obtained after about 6 wk of intrathecal therapy and at that time, relapse of the BM leukemia occurred. BM cytogenetic analysis showed further clonal evolution: $47, \mathrm{XY},+8, \mathrm{t}(7 ; 12)$ $(q 36 ; p l 3)$ in four metaphases, $49, \mathrm{XYY},+8,+8, \mathrm{t}(7 ; 12)(\mathrm{q} 36 ; \mathrm{pl} 3)$ in two metaphases and $50, \mathrm{XYY},+8,+8, \mathrm{t}(7 ; 12)(\mathrm{q} 36 ; \mathrm{pl} 3),+19$ in 36 metaphases. Most of the cells showed a tetrasomie 8 , trisomie 19 , and an additonal $Y$ chromosome, next to the translocation $(7 ; 12)$ already described at diagnosis. A second remission could not be reached and the patient died $6 \frac{1 / 2}{2}$ months after the onset of the disease.

therapy. If no remission was obtained, the following regimes were tried: daunomycine (with or without vincristine) combined with prednisone, or a modified VAMP (vincristine, methotrexate, 6mercaptopurine and prednisone) regime.

Remission was achieved with ARA-C and CYT in three patients with AML (no. 3, 4, and 5) and two patients with EL (no. 14 and 15). Additional treatment with VAMP resulted in remission in two patients with AML and AMMoL, respectively (no. 6 and 13). Such additional treatment with vincristine and daunomycine resulted in remission in one patient with AMMoL (no. 11). The only patient not initially treated with ARA-C and CYT achieved remission with VAMP induction therapy (no. 8). Two patients died during induction therapy (patients 7 and 10), and in three patients, remission could not be achieved (no. 9, 12, 16).

\section{CYTOGENETIC ANALYSIS}

Chromosome analyses were done on BM cells immediately suspended in Ham's F 10 medium containing colchicine $(0,25 \mu \mathrm{g} /$ $\mathrm{ml}$ ). Short time cultures of BM were also performed in partly conditioned medium made of three volumes of fresh Ham's F10 medium supplemented with $15 \%$ fetal calf serum and two volumes of similar medium, conditioned on a fibroblast culture. For the two more recently studied patients ( 8 and 13$)$ a modification of the synchronization method by methotrexate treatment of the culture was used. This method improves considerably the morphology of chromosomes in metaphases of leukemic cells (6). Whole blood was cultured for 24 and $48 \mathrm{hr}$ without phytohemagglutinin. A 48 or $72 \mathrm{hr}$ lymphocyte culture (peripheral blood, stimulated with phytohemagglutinin) was used as a control, whenever possible. In all cultures, chromosomes were identified with at least one (usually more) of the different banding techniques: Gbands by acetic saline using Giemsa, Q-bands by fluorescence using Quinacrine, and R-bands by fluorescence using acridine orange according to the nomenclature of the Paris Conference (1971), supplement (1975) (15). The number of cells examined per analysis varied between $20-50$ depending on the quality of the culture and the findings in the first batch of 20 cells. In order to distinguish mosaicism from random aneuploidy, it was considered that for structural abnormalities, the presence of two cells with a similar aberration was enough to define a clonal subpopulation and that for numerical abnormalities, three cells with the same aneuploidy were required.

\section{RESULTS}

The results of chromosomal analyses are presented in Table 2 and illustrated in Figures 1-7.

BM cells of the two CML patients were $\mathrm{Ph}^{1}(+)$ with the classical translocation $(9 q+; 22 q-)$.

BM cytogenetic analysis of the 14 patients with ANLL revealed in five patients (no. 4, 5, 7, 11, and 14) the absence of acquired chromosomal abnormalities and in the other nine patients, the presence of an abnormal clone of cells at diagnosis. In six of these nine patients, cells with a normal karyotype were observed next to the abnormal clone. Six had an abnormal karyotype with 46 chromosomes, two with 47 and one with 51 ; the abnormal karyotypes were all different, but some changes were repeatedly found in variable associations with other numerical or structural aberrations.

Trisomy 8 was found three times (no. 10, 13, and 16) together with translocation $(7 ; 12)$ (no. 13; Fig. 1a), monosomy 7 (no. 10; 
Fig. 1b) and in a clonal population of 51 chromosomes $(+Y,+8$, $+15,+2 G$ ) (no. 16). The other numerical abnormalities observed were trisomy 19 (no. 3; Fig. 2), monosomy 7 (no. 10; Fig. lb), and monosomy 21 in part of the BM cells of patients 3 and 9 , indicating further clonal evolution in these two cases.
Deletion of the long arm of chromosome 7 was observed twice with slightly different breakpoints: in patient $9 \mathrm{G}$-banding seems to indicate a break in band (7) (q21 or q22) (Fig. Ic) and in patient 8 , the breakpoint is clearly more distal, probably in band (7) (q31) (Fig. 4). Deletions of other chromosomes were also observed:

Table 2. Cytogenetic Analysis

\begin{tabular}{|c|c|c|c|c|c|}
\hline Patient & Diagnosis & Clinical phase & $\begin{array}{l}\text { No. of cells ana- } \\
\text { lysed }^{1}\end{array}$ & Karyotype & Illustrations \\
\hline \multirow[t]{2}{*}{1} & CML & Diagnosis & 26 & $46, X X, G q-$ & \\
\hline & & Chronic & 20 & $46, X X, t(9 q+; 22 q-)(95 \%) / 46, X X(5 \%)$ & \\
\hline \multirow[t]{2}{*}{2} & CML & Diagnosis & 35 & $46, X X, t(9 q+; 22 q-)$ & \\
\hline & & Chronic & 32 & $46, X X, t(9 g q+; 22 q-)$ & \\
\hline 3 & AML & Diagnosis & 44 & $47, X Y, 1 p-,+19(80 \%) / 46, X Y, 1 p-,+19,-21(20 \%)$ & Figures 2 and 3 \\
\hline 4 & AML & Diagnosis & 32 & $46, X Y$ & \\
\hline 5 & AML & Diagnosis & 34 & $46, X Y$ & \\
\hline \multirow[t]{4}{*}{6} & AML & Diagnosis & 37 & $46, X Y, t(12 p+; 22 q-)(80 \%) / 46, X Y(20 \%)$ & Figure 5 \\
\hline & & Remission & 40 & $46, X Y$ & \\
\hline & & Remission & 32 & $46, X Y$ & \\
\hline & & Remission & 34 & $46, X Y$ & \\
\hline 7 & APL & Diagnosis & 24 & $46, X Y$ & \\
\hline \multirow[t]{2}{*}{8} & APL & Diagnosis & 40 & $46, X X, 4 q+, 7 q-, t(8 ; 21), 9 q-(80 \%) / 46, X X(20 \%)$ & Figure 4 \\
\hline & & Remission & 50 & $46, \mathrm{XX}$ & \\
\hline 9 & AMMoL & Diagnosis & 78 & $\begin{array}{l}46, X X, 7 q-(85 \%) / 45, X X, 7 q-,-21(15 \%) / \\
46, X X(\text { one cell })\end{array}$ & Figure lc \\
\hline 10 & AMMoL & Diagnosis & 50 & $46, X Y,-7,+8$ & Figure $1 b$ \\
\hline 11 & AMMoL & Diagnosis & 50 & $46, \mathrm{XY}(80 \%) / 35 \rightarrow 45$ hypodiploidy $(20 \%)$ & \\
\hline \multirow[t]{2}{*}{12} & AMMoL & Diagnosis & 52 & $46, X X, t(11 ; 13)(90 \%) / 46, X X(10 \%)$ & Figure 7 \\
\hline & & Terminal & 6 & $46, \mathrm{XX}, \mathrm{t}(11 ; 13)$ & \\
\hline \multirow[t]{2}{*}{13} & AMMoL & Diagnosis & 33 & $47, X Y,+8, t(7 ; 12)$ & \\
\hline & & Incomplete Remission & 50 & $46, X Y / 47, X Y,+8, t(7 ; 12)($ one cell). & Figure 1a \\
\hline 14 & EL & Diagnosis & 45 & $47, X Y,+21^{2}$ & \\
\hline 15 & EL & Diagnosis & 29 & $46, X X, t(4 ; 16)(65 \%) / 46, X X(35 \%)$ & Figure 6 \\
\hline 16 & EL & Diagnosis & 57 & $46, X Y(88 \%) / 51, X Y,+Y,+8,+15,+2 G(12 \%)$ & \\
\hline
\end{tabular}

' BM cells and/or unstimulated blood cultures.

${ }^{2}$ Down's syndrome.

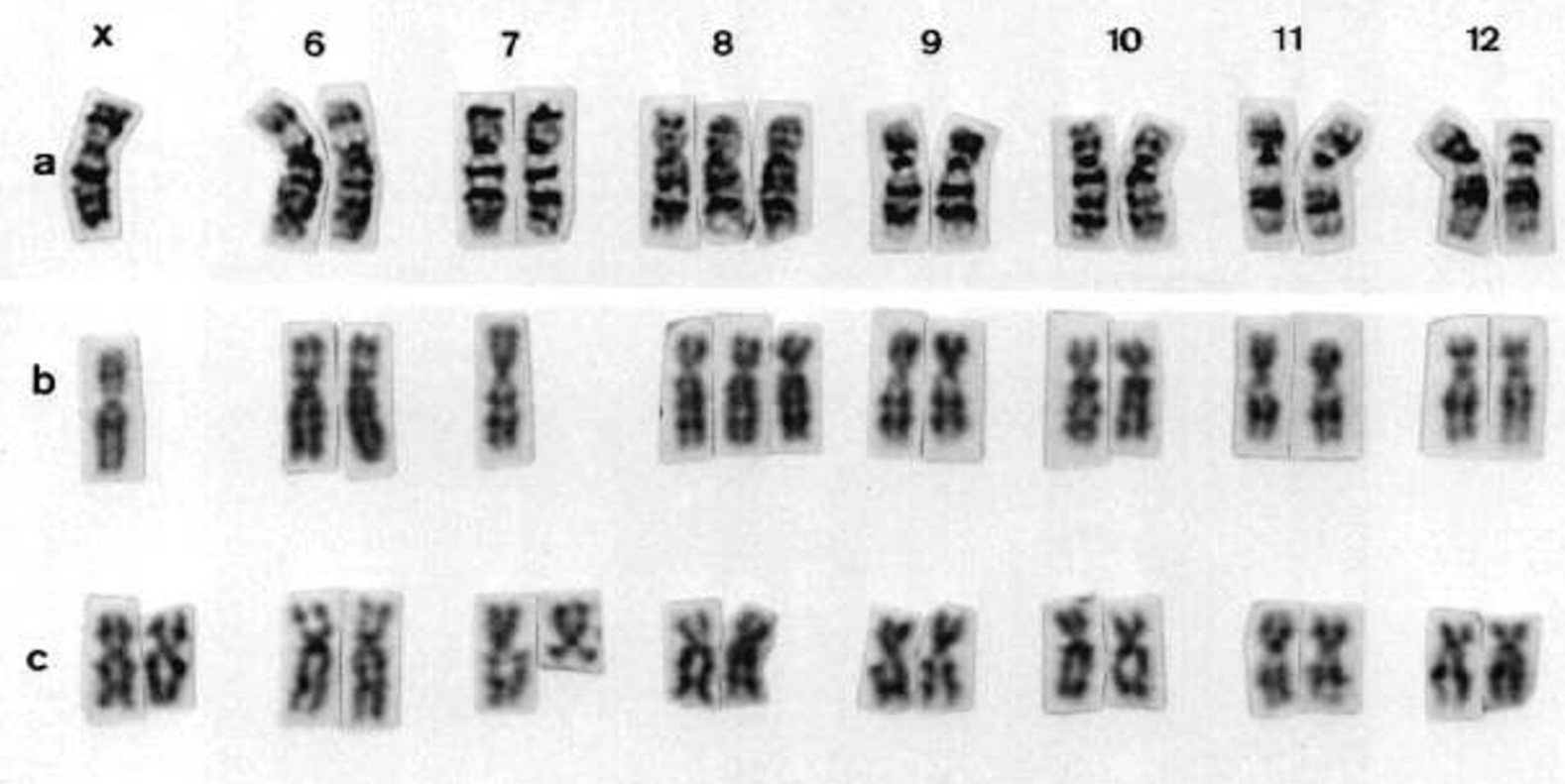

Fig. 1. C-group chromosomes from BM karyolypes of tiuce different patients cemonstrating nonrandom abonormalities: $a$ trom patient $1 \hat{s}$ with trisomy 8 and translocation $(7 ; 12)(\mathrm{q} 36 ; \mathrm{p} 13)$; $b$ from patient 10 with monosomy 7 and trisomy $8 ; c$ from patient 9 with deletion $(7)(\mathrm{q} 22)$. G-banding with trypsine $(a)$ and with ASG ( $b$ and $c$ ). 
interstitial deletion (1) (p22p32) in patient 3 (Figs. 2 and 3) and interstitial deletion of (9) (q22q32) in patient 8 (Fig. 4).

A translocation $(8 ; 21)(\mathrm{q} 21 ; \mathrm{q} 211)$ similar to the rearrangement often described in AML $(13,21,23)$ has been found in the karyotype of patient 8 together with a $4 q+$ (probably duplication of band (4) (q31)) and deletions of chromosomes 7 and 9 already mentioned (Fig. 4). The translocation $(7 ; 12)(\mathrm{q} 36 ; \mathrm{pl} 13)$ in patient 13 involves small parts of these chromosomes; the $7 q+$ in particular was difficult to visualize with Trypsin-Giemsa banding (Fig. la), but was identified without any doubt with R-banding.

Apparently balanced translocations were found in three patients (no. $6,12,15)$ as the only anomaly. The $t(12 p+; 22 q-$ ) is a variant of the $\mathrm{Ph}^{1}$ anomaly with translocation of the long arm of 22 onto the short arm of 12 (no. 6; Fig. 5). The reciprocal translocation between chromosomes 4 and 16, found in patient no. 15, is illustrated in Figure 6 and a complex translocation between chromosomes 11 and 13 in Figure 7 (no. 12). In combining the different banding techniques, the rearrangement in patient no. 12 most likely was a two-step event: a pericentric inversion of chromosome 11 (per.inv.(11)(p12;q23)), followed by a reciprocal translocation between the inv.(11) and chromosome 13 (q23;q21). The two derivating chromosomes could be described as follows: $\operatorname{der}(11)$ as $13 q$ ter $\rightarrow 13 q 21:: 11 \mathrm{p} 12 \rightarrow 11 \mathrm{q} 22:: 11 \mathrm{p} 13 \rightarrow 11$ pter and $\operatorname{der}(13)$ as 13 pter $\rightarrow 13 q 21:: 11$ q24 $\rightarrow 1$ lqter.

In most BM cytogenetic analyses of this study, hypodiploidy was found with random loss of chromosomes but without any clonal pattern, and always below the $5 \%$ level. As an exception, a $20 \%$ level of hypodiploidy was found in one patient (no. 11).

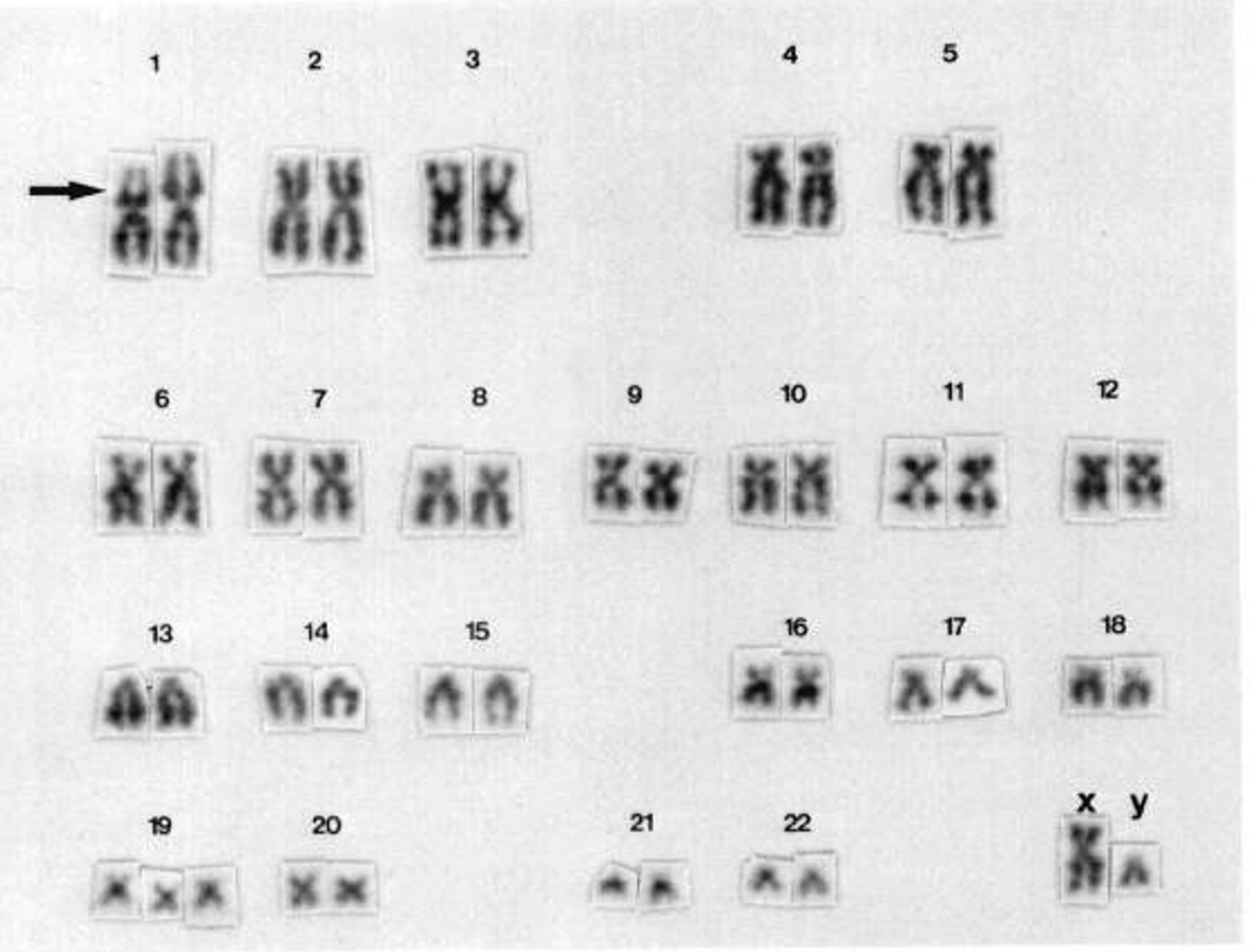

Fig. 2. Karyotype of the main BM cell population of patient 3. Note the interstitial deletion (1)(p22p32) and trisomy 19. ASG-technique.

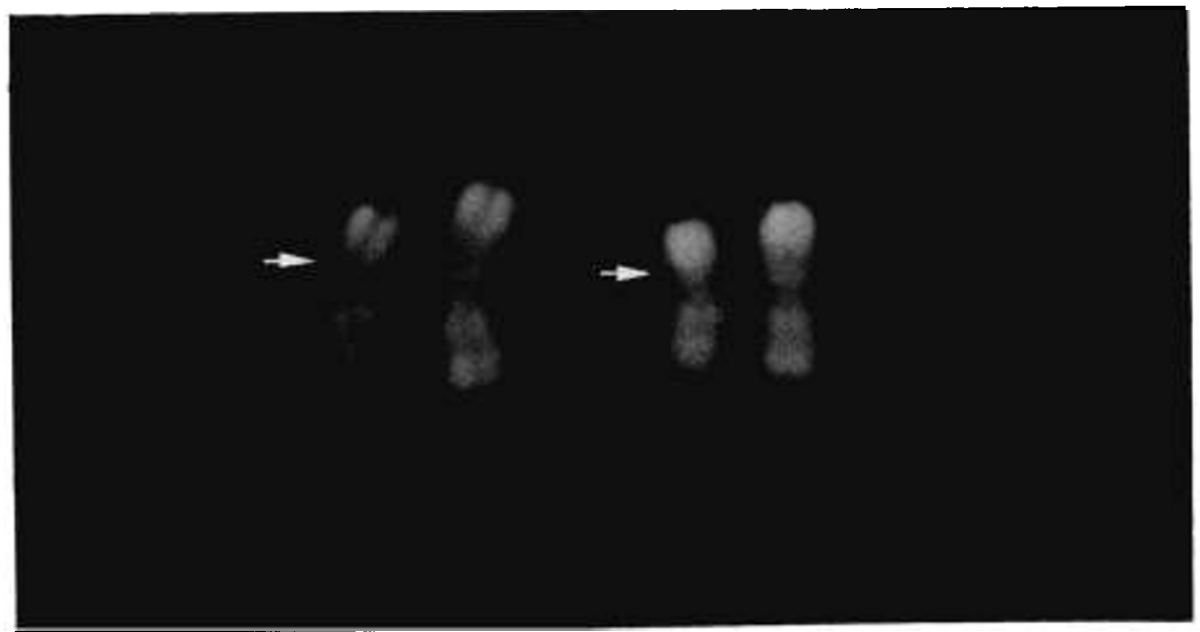

Fig. 3. Chromosome pair no. 1 from two cells of patient 3 demonstrating the interstitial deletion (1)(p22p32). R-banding with acridine orange. 


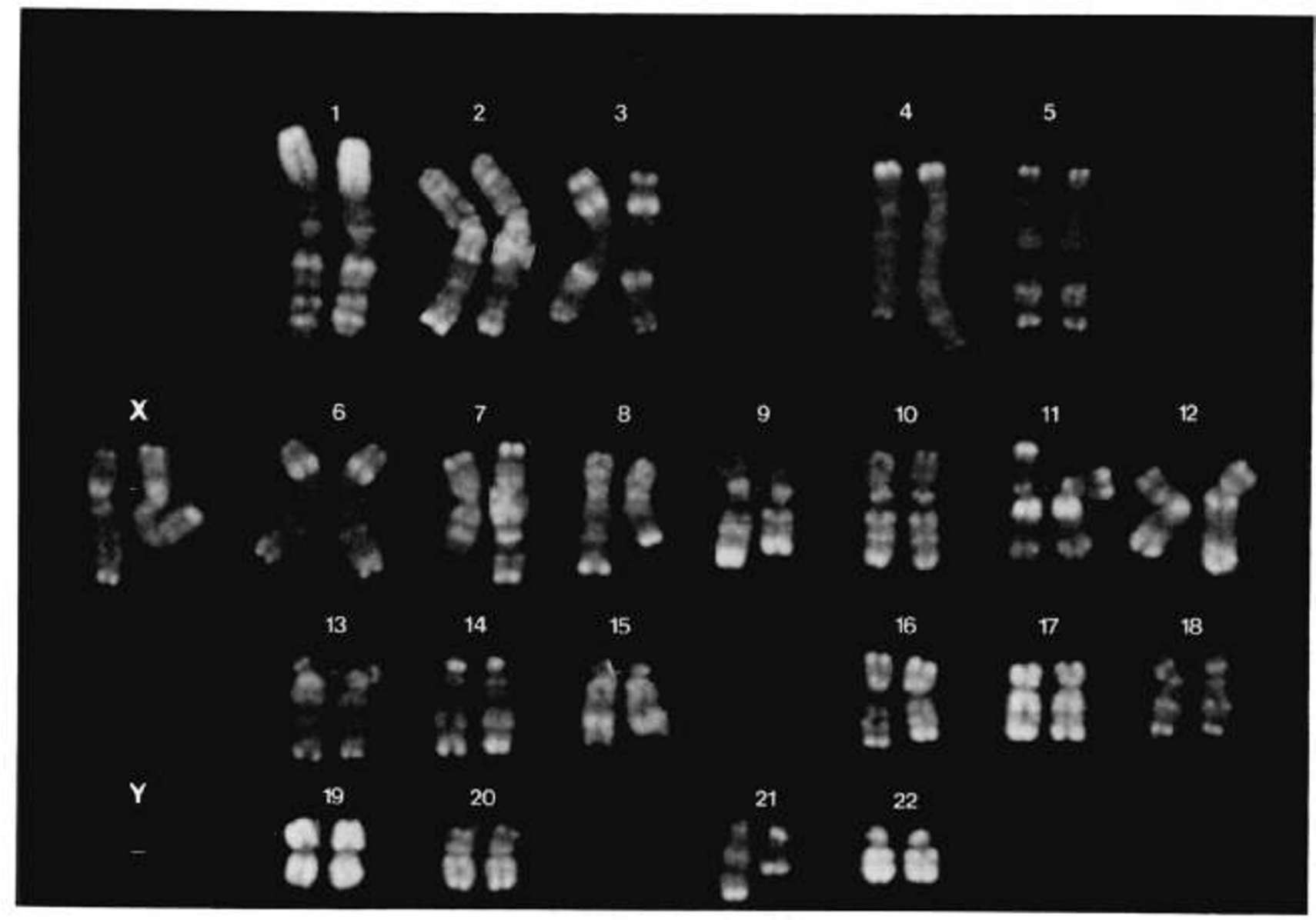

Fig. 4. BM karyotype of patient $8: 46, X X, 4 q+$, del $(7)(q 31), t(8 ; 21)(q 21 ; q 211)$, del $(9)(q 22 q 32)$. The $4 q+$ results probably from a duplication of band (4)( $\mathrm{q} 31)$. R-banding with acridine orange.

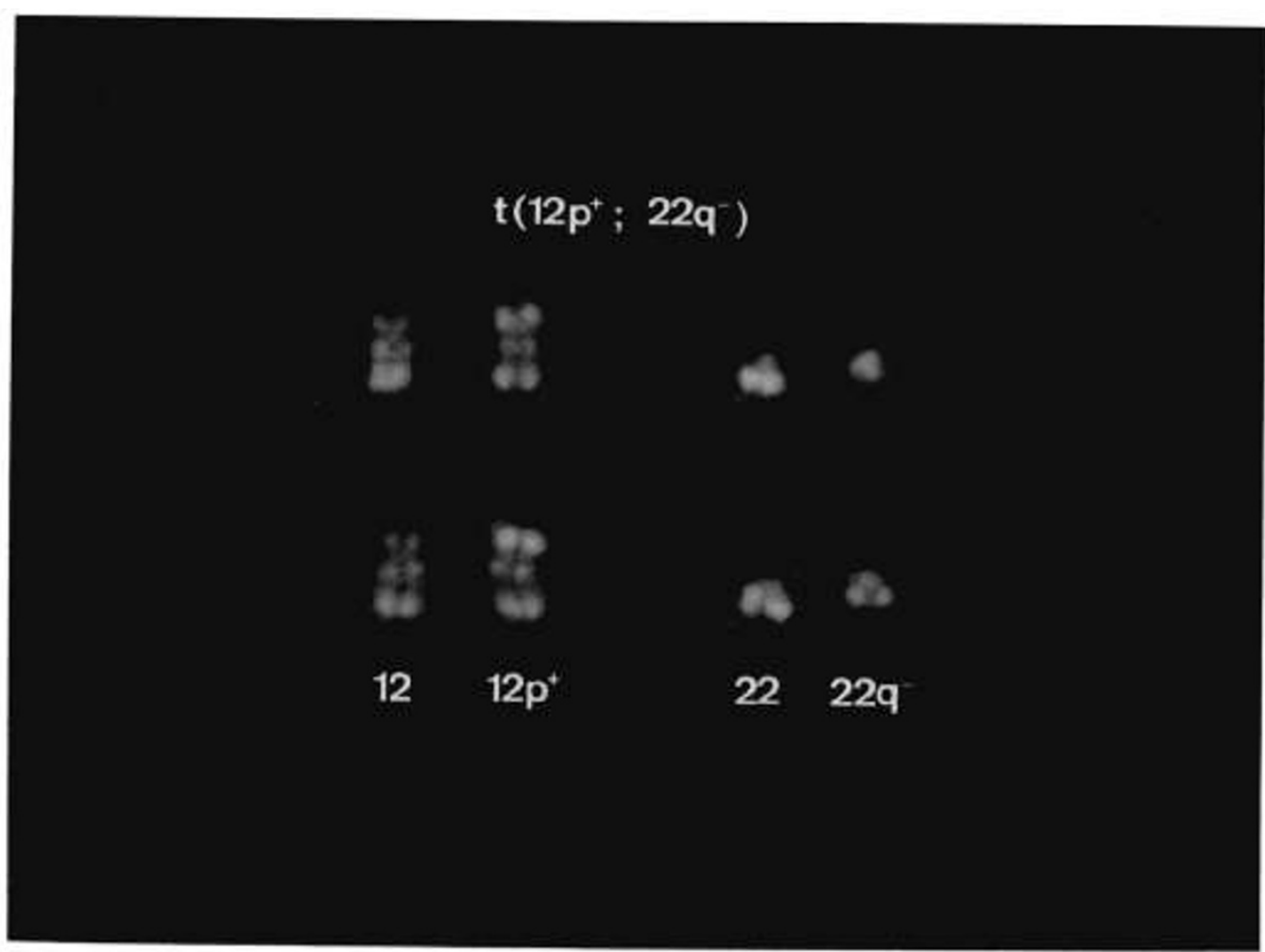

Fig. 5. Chromosome pairs 12 and 22 from two cells of patient 6 showing translocation $(12 p+; 22 q-)$, a variant of the Philadelphia anomaly. Rbanding with acridine orange. 
The lymphocyte karyotype, was always found to be normal with one exception: patient 14 with Down's syndrome showed the expected trisomy 21 . This is particularly important in cases where an apparently balanced translocation in the BM was found. The

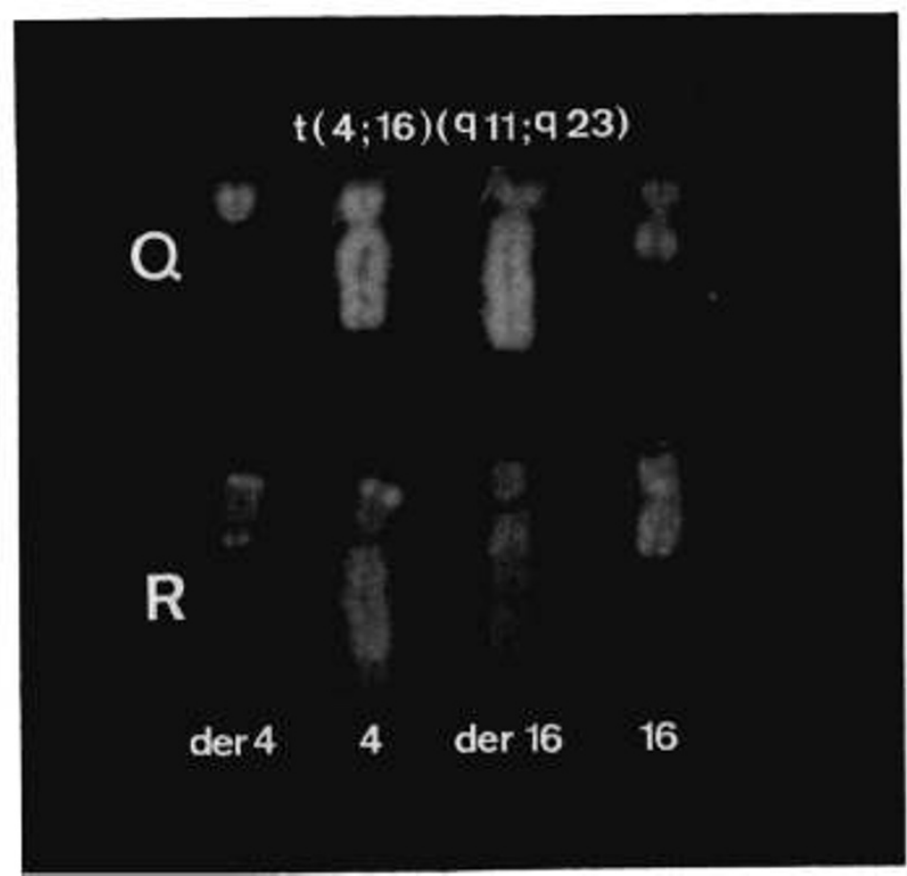

Fig. 6. Chromosome pairs 4 and 16 from two cells of patient 15 demonstrating translocation $(4 ; 16)(\mathrm{q} 11 ; \mathrm{q} 23)$. Above Q-banding with atebrine and below R-banding with acridine orange. absence of lymphocytes in peripheral blood in patient 3 and the short survival of patient 10 prevented a lymphocyte culture.

Followup cytogenetic studies were performed in six cases. In the two CML patients, the $\mathrm{Ph}^{1}$ chromosome persisted during the chronic phase. In two patients with ANLL, hematologic remission was accompanied by normalization of the BM karyotype (no. 6 and 8 ). In patient 13 , incomplete remission with $16 \%$ blast cells in BM was found together with normalization of the BM karyotype in all but one cell. One month later, hematologic remission was achieved, but CNS leukemia was then diagnosed. Cytogenetic analysis of 32 cells from the cerebrospinal fluid revealed the same karyotypic abnormalities as found in BM at diagnosis. In one patient (no. 12) in whom remission was not achieved, generalization of the abnormal karyotype was seen in the terminal phase of the disease.

\section{DISCUSSION}

The findings in our two patients with CML proved them to suffer from the adult type of this disease: both showed the $\mathrm{Ph}^{1}$ chromosome in BM cells and did not have a raised level of fetal hemoglobin. Response to busulfan therapy was satisfactory and both children are still in the chronic phase of their disease after 5.5 and $4.5 \mathrm{yr}$, respectively, needing only intermittent therapy.

Acquired cytogenetic abnormalities in leukemic cells were found in 9 of 14 children with ANLL. Comparison of this material with four adult series studied with the use of banding techniques is presented in Table 3 . The distribution of nonrandom and random abnormalities is comparable in the five series of patients. The excess of nonrandom abnormalities involving chromosome 7 (monosomy, deletion), chromosome 8 (trisomy, translocation $8 ; 21$ ), and chromosome 21 are often stressed, but in adults as well as in children, these nonrandom abnormalities are often associated with other numerical or structural aberrations. Random, appar-

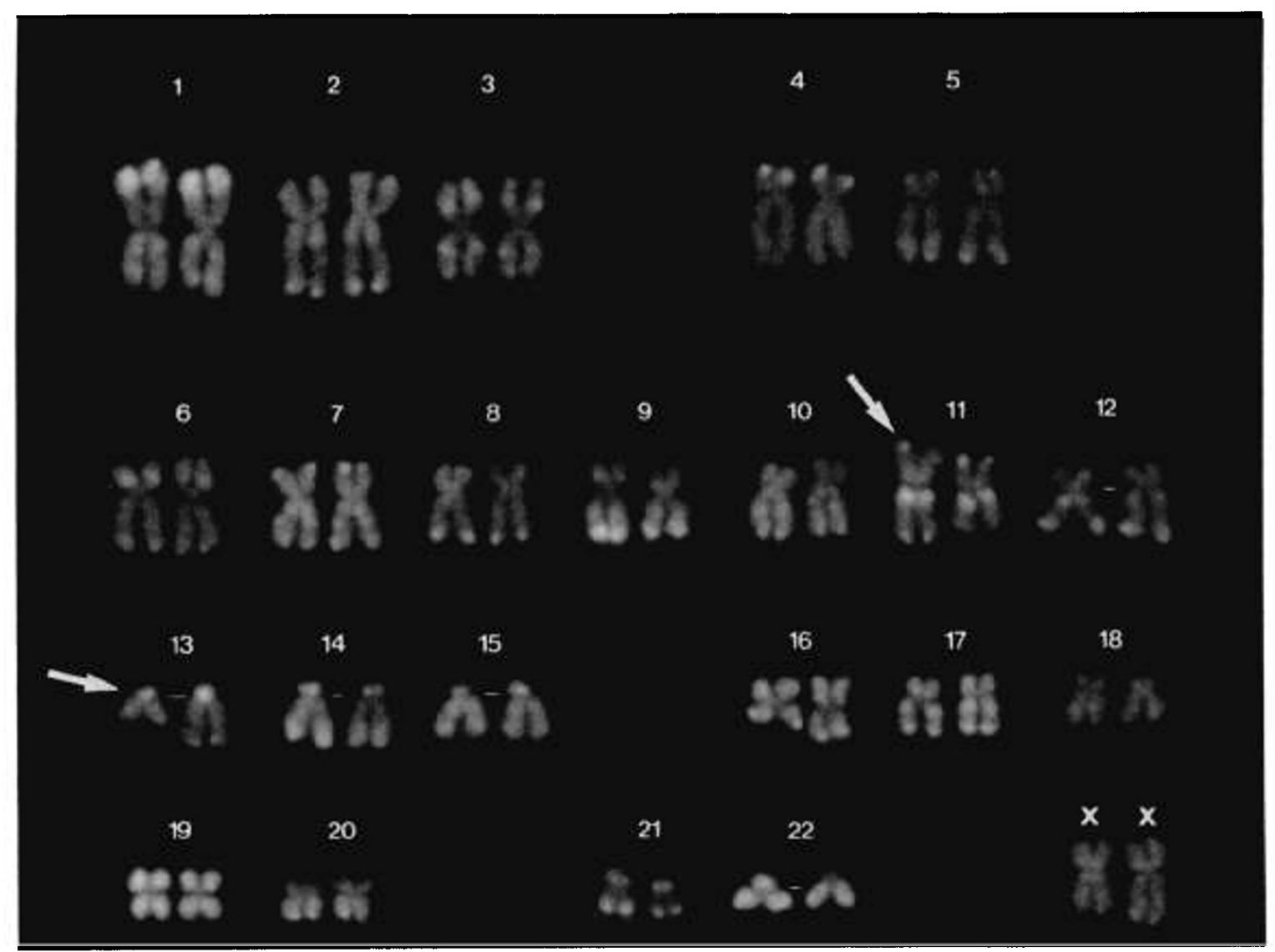

Fig. 7. Karyotype of patient 12 with translocation $(11 ; 13)$ and congenital leukemia. See text for interpretation of the 2 derivative chromosomes indicated by arrow. R-banding with acridine orange. 
Table 3. Literature survey of random and nonrandom chromosomal abnormalities in ANLL

\begin{tabular}{|c|c|c|c|c|c|c|c|c|c|c|}
\hline \multicolumn{2}{|c|}{ Patient material } & \multicolumn{6}{|c|}{ Nonrandom ${ }^{1}$} & \multicolumn{2}{|c|}{ Random $^{1}$} & \multirow[b]{2}{*}{ Reference } \\
\hline Total & $\begin{array}{l}\text { With abnormal } \\
\text { clone }\end{array}$ & +8 & -7 & +21 & -21 & $\mathrm{t}(8 ; 21)$ & $7 q-$ & $\begin{array}{c}\text { Balanced transloca- } \\
\text { tions }\end{array}$ & Deletions & \\
\hline 38 adults & 16 & 3 & 0 & 1 & 2 & 3 & 1 & 11 & 4 & 13 \\
\hline 30 adults & 17 & 9 & 4 & 3 & 1 & 0 & 0 & 0 & 0 & 10 \\
\hline 50 adults & 25 & 2 & 4 & 0 & 1 & 2 & 0 & 8 & 12 & 20 \\
\hline 36 adults & 20 & 2 & 4 & 2 & 1 & 2 & 1 & 4 & 11 & 22 \\
\hline 14 children & 9 & 3 & 1 & 0 & 2 & 1 & 2 & 4 & 2 & This report \\
\hline
\end{tabular}

' Not all karyotypic abnormalities have been tabulated but only those corresponding to the headings; complete descriptions of the individual karyotypes are given in the original publications and Table 2 for the patients presented here.

ently balanced translocations are also often observed in a relatively large number of patients. The series of Mitelman et al. (11) is an exception: in 17 AML patients with abnormal clones in BM cells, he found mostly numerical abnormalities of the nonrandom type, only 2 structural abnormalities ring (7), and isochromosome (17q) and no translocation. This could probably be explained by a clinically more homogenous group of patients, restricted to a diagnosis of AML.

The $\mathrm{Ph}^{1}$ chromosome has occasionally been reported in AML $(5,12,25,27)$. The variant of the $\mathrm{Ph}^{1}$ chromosome $t(12 \mathrm{p}+; 22 \mathrm{q}-)$ in patient 6 is of particular interest because it raises the question whether this case represented $\mathrm{Ph}^{1}(+) \mathrm{AML}$ or $\mathrm{CML}$ presenting with a blast crisis $(16,22)$. In $\mathrm{Ph}^{1}(+)$ blast leukemia in young children, a mixed BM morphology with myeloid and lymphoid characteristics has been reported (3). Exact distinction between AML or CML blast crisis is important in view of the therapeutic implications. The following features suggest a diagnosis of AML in patient 6:1) absence of splenomegaly; 2) absence of increased eosinophils and basophils in BM morphology at diagnosis; 3) cytogenetic mosaicism, the $\mathrm{Ph}^{1}$ being present in $80 \%$ of the $\mathrm{BM}$ metaphases at the time of diagnosis; 4) successful induction of remission; 5) persistent cytogenetic remission accompanying the hematologic and clinical remission; 6) normalization of BM morphology during remission without left shift of myelopoiesis, which, if present, would suggest CML. This patient represents the second case with a $\mathrm{Ph}^{1}$ variant consisting of a translocation between chromosomes 12 and 22 : $t(12 p+; 22 q-)$ instead of the classical $\mathrm{t}(9 \mathrm{q}+; 22 \mathrm{q}-)$. Blij-Philipsen et al. have reported a similar $\mathrm{Ph}^{1}$ variant in an adult with $C M L$.

A translocation between chromosomes 15 and $17: \mathrm{t}(15 ; 17)$ $(\mathrm{q} 22 ; \mathrm{q} 21)$ has been suggested to be specific of APL and has been reported in at least nine cases $(21,22)$. Such a rearrangement was not observed in our two cases with APL: patient 7 had a normal karyotype and patient 8 presented with the nonrandom $t(8 ; 21)$ associated with $4 q+$, del (7) (q31), and interstitial del (9) (q22q32). Two other reported cases of APL share at least partially the karyotypic changes of this last patient: a 41-yr-old woman had the $t(8 ; 21)(20)$ and a 38-yr-old man presented deletions (7) (q22), and (9) (q22), together with translocation $(15 ; 17)(21)$.

The use of complementary banding techniques like $R-$ and $G-$ or Q- allowed us to identify interstitial deletions in two cases: deletion (1) (p22p32) in patient 3 and deletion (9) (q22q32) in patient 8 . Other more specific interstitial deletions have been observed in malignant or potentially malignant cells: deletion (13) (q14) was found in 14 cases of retinoblastoma (30), deletion (11) (p12p14) in three cases of aniridia syndrome with a high frequency of Wilms tumor (18) and interstitial deletion $5 q$ has been reported in refractory anemia and leukemia $(26,29)$.

Improvement of remission rate and survival have been repeatedly associated with the presence in BM of cells with a normal karyotype $(4,13,24)$. Although our observations concern only a small number of patients, they show the same trend: of the five patients with a normal BM karyotype at diagnosis, one died during induction therapy and the four others achieved remission; the mean survival time was 17 months, one of them is still alive and in complete remission (no. 5). Of the six patients with a mosaicism at presentation, remission was achieved in three; their mean survival time is 7 months, two patients being still alive and in remission (no. 6 and 8 ). Three patients had only abnormal cells in their BM at presentation, complete remission was achieved in one patient (no. 3); hematologic remission was obtained in another (no. 13), but simultaneously CNS dissemination with karyotypically abnormal cells only occurred. The third patient resisted therapy (no. 10). In this group, the mean survival time is 5 months.

It has already been shown, that AML has a better prognosis than AMMoL and even more so if it is associated with a more favorable cytogenetic picture (4). Among our patients, all receiving the same initial treatment for their ANLL, children with AML showed a higher rate of successful induction of remission and a longer mean survival. All four patients with AML achieved remission; of the five patients with AMMoL, hematologic remission was achieved only once, and of the three patients with EL, two children reached remission. Among the eight patients with $A M M o L$ or EL, a clearly longer survival is found in the two patients without acquired karyotypic abnormalities in their BM.

Followup studies may be valuable in establishing prognosis, because they give an insight into the reaction to therapy of abnormal cell populations labeled by chromosomal markers. In our series of patients, such studies confirmed hematologic remission by cytogenetic remission in patients 6,8 , and 13 and showed that generalization of the abnormal clone accompanied a fatal outcome in patient 12. The rapid evolution of abnormal clones into subpopulations, as already seen at diagnosis in patients 3 and 9 , may carry an unfavorable prognosis.

BM cytogenetic analyses in childhood ANLL confirmed what has been found in the adult population: an excess of nonrandom chromosome abnormalities. Their significance for oncogenesis, diagnosis, and prognosis is still unclear. Large series in which modern banding techniques are applied would improve the understanding of the different random abnormalities. In a complex way, these may involve similar chromosomal regions or similar mechanisms such as resulting in interstitial deletions and isochromosomes. Another way to study the significance of specific, nonrandom chromosome abnormalities in the development of leukemia would be to introduce these particular chromosomes in animal cells using the interspecies somatic cell hybridization techniques. This approach has been attempted by Engel $e t$ al. in 1976 (2) for the $\mathrm{Ph}^{1}$ chromosome and similar experiments are in progress in this department.

\section{REFERENCES AND NOTES}

1. Blij-Philipsen M. van der, Breed, W. P. M.., and Hustinx, T. W. J.: A case of chronic myeloid leukemia with a translocation $(12 ; 22)$ (pl3:q11). Hum. Genet. 39: 229 (1977).

2. Engel, E., McGee, B. J., Russēll, M. H. Cassidy, P. S., Flexner, J. M., and Engelde Montmollin, M. L.: Transformation of mouse cells by fusion with chronic granulocytic leukemia cells: possible role of human chromosome 7. Ann. Génét., 19: 249 (1976).

3. Forman, E. N., Padre-Mendoza, T., Smith, P. S., Barker, B. E., and Farnes, P. $\mathrm{Ph}^{1}$-positive childhood leukaemias: spectrum of lymphoid-myeloid expressions. Blood, 49: 549 (1977).

4. Golomb, H. M., Vardiman, J., and Rowley, J. D.: Acute non-lymphocytic leukemia in adults: correlations with Q-banded chromosomes. Blood, 48: 9 (1976) 
5. Gustavson, A., Mitelman, F., and Olsson, I.: Acute myeloid leukaemia with Philadelphia chromosome. Scand. J. Haematol., 19: 449 (1977).

6. Hagemeijer, A., Smit, E. M. E., and Bootsma, D.: Improved identification of chromosomes of leukemic cells in methotrexate treated cultures. Cytogenet. Cell Genet., 23: 200 (1979).

7. Kaufmann, U., Löfler, H., Foerster, W., Desaga, J. F., and Koch, F.: Fehlendes chromosom $\mathrm{Nr} .7$ in der präleukamischen phase einer myeloblastenleucose be einem kind. Blut, 29: 50 (1974).

8. Lampert, F., Phebus, C. K., Huhn, D., Mtyer, G., and Greiffenegger, M., Leukemic Xanthomatosis with a missing no. 9 chromosome. Z. Kinderheilk., 112: 251 (1972).

9. Lawler, S. D., Secker Walker, L. M., Summersgill, B. M., Reeves, B. R., Lewis, J., Kay, H. E. M., and Hardisty, R. M.: Chromosome banding studies in acute leukemia at diagnosis. Scand. J. Haematol., 15: 312 (1975).

10. Macdougall, L. G., Brown, J. A., Cohen, M. M., and Judisch, J. M.: C-monosomy myeloproliferative syndrome: a case of 7-monosomy. J. Pediatr., 84: 256 (1974)

11. Mitelman, F., Nilsson, P. G., Levan, G., and Brandt, L.: Non-random chromosome changes in acute myeloid leukemia - Chromosome banding examination of 30 cases at diagnosis. Int. J. Cancer, 18: 31 (1976).

12. Nagao, K. Yonemitsu. H., Yamaguchi, K., and Okuda, K.: A case of acute myeloblastic leukemia with $\mathrm{Ph}^{3}$ chromosome showing translocation $9 \mathrm{q}+; 22 \mathrm{q}-$. Blood, 50: 259 (1977).

13. Nilsson, P. G., Brandt, L., and Mitelman, F.: Prognostic implications of chromosome analysis in acute non-lymphocytic leukemia. Leukemia Res., 1: 3 (1977).

14. Oshimura, M., Hayata, I., Kakati, S.. and Sandberg, A. A.: Chromosomes and causation of human cancer and leukemia. XVII. Banding studies in acute myeloblastic leukemia (AML). Cancer, 38: 748 (1976).

15. Paris Conference (1971), Supplement (1975): Standardization in human cytogenetics. Birth Defects: Original Article Series, Vol. 11, no. 9 (The National Foundation, New York).

16. Peterson, L. T., Bloomfield, C. D., and Brunning, R. D.: Blast crisis as an initia or terminal manifestation of chronic myeloid leukemia. Am. J. Med., 60: 209 (1976).

17. Petit, P., Alexander, M., and Fondu, P.: Monosomy 7 in erythroleukemia. Lancet, 2: 1326 (1973).

18. Riccardi, V. M., Sujanski, E., Smith, A. C., and Francke, U.: Chromosomal imbalance in the aniridia-Wilms' tumor association: $11 \mathrm{p}$ interstitial deletion. Pediatrics, 61: 604 (1978)

19. Rowley, J. D.: A new consistent chromosomal abnormality in chronic myeloge- nous leukemia identified by quinacrine fluorescence and Giemsa staining. Nature, 243: 290 (1973)

20. Rowley, J. D.: Identification of a translocation with quinacrine fluorescence in a patient with acute leukemia. Ann. Genet., 16: 109 (1973).

21. Rowley, J. D.: The cytogenetics of acute leukemia. Clin. Haematol., 7: 385 (1978).

22. Rowley, J. D., and de la Chapelle, A.: Chromosomes in leukemia. General report on the First International Workshop on Chromosomes in Leukemia. Cytogenet. Cell Genet., 19: 321 (1977).

23. Rowley, J. D., and Potter, D.: Chromosome banding patterns in acute nonlymphocytic leukemia. Blood, 47: 705 (1976).

24. Sakurai, M. and Sandberg, A. A. Chromosomes and causation of human cance and leukemia. XI Correlations of karyotypes with clinical features of acute myeloblastic leukemia. Cancer, 37: 285 (1976).

25. Sasaki, M.. Muramoto, J., Makino, S., Hara, M. J. A. Y., Okada, M., and Tanaka E.: Two cases of acute myeloblastic leukemia associated with a 9/22 translocation. Proc. Jap. Acad., 5l: 193 (1975).

A., Moriau, M., De Bruyere, M., and Sonnet, J.: A new hematologic syndrome with a distinct karyotype: the 5q-chromosome. Blood, 46: 519 (1975).

27. Sonta, S., Oshimura, M., and Sandberg, A. A.: Cytogenetically unusual cases of leukemia. Blood, 48: 697 (1976)

28. Sonta, S., and Sandberg, A. A.: Chromosomes and causation of human cancer and leukemia. XXIV Unusual and complex $\mathrm{Ph}^{1}$ translocations and their clinical significance. Blood, 50: 691 (1977).

29. Van den Berghe, H., David, G., Michaux, I. L., Sokal, G., and Verwilghen, R.: $5 q$ - Acute myelogenous leukemia. Blood, 48: 624 (1976).

30. Wilson, M. G., Ebbin, A. J., Towner, J. W., and Spencer, W. A.: Chromosomal anomalies in patients with retinoblastoma. Clin. Genet., 12:1 (1977).

31. Zuelzer, W. W., Inoue, S., Thompson, R. I., and Ottenbreit, M. J.: Long-term cytogenetic studies in acute leukemia of children; The nature of relapse. Am. J. Hematol., l: 143 (1976)

32. The authors thank W. Sizoo M. D. for referring one patient, Professor D Bootsma for encouragement and support, and E. R. van Wering M. D. and E. Vissers-Praalder of the Dutch Study Group for Childhood Leukemia for morphologic study of the bone marrow smears.

33. Requests for reprints should be addressed to: A. Hagemeijer, M. D., Department of Cell Biology and Genetics, Erasmus University, P. O. Box 1738, Rotterdam, The Netherlands.

34. Received for publication October 5, 1978.

35. Accepted for publication February 1, 1979. 